\title{
Jarak dan Sudut Antara Dua Matriks Berdimensi Sama
}

\author{
AgAh D. Garnadi ${ }^{1}$ \\ Jurusan Matematika, Fakultas MIPA \\ Institut Pertanian Bogor, Indonesia \\ e-mail: agah.garnadi@gmail.com
}

Teruntuk Prof. Dr. Siswadi, MSc., yang memasuki usia ke 70 tahun.

\begin{abstract}
Abstrak
Dengan memanfaatkan rumus sudut antara dua subruang yang diberikan oleh Gunawan dan sejawat, didapatkan sepasang sudut antara dua matriks, berdasarkan subruang kolom dan subruang baris dari kedua matriks. Sementara nilai-singular dari masing-masing matriks, digunakan untuk menghitung jarak antara kedua matriks tersebut. Dengan demikian, diperoleh representasi jarak, dan sepasang sudut antara dua matriks yang berukuran sama.

Kata kunci: Matriks, sudut, subruang, aljabar linear
\end{abstract}

\begin{abstract}
In this note, we demonstrate how to compute a pair of angles between two matrices of the same size. Thanks to the formula of angles between two subspaces given by Gunawan et al., the pair of angles between two matrices of the same size is easily computed. At the same time, the distance between the two matrices also found.

Keywords: Matrix, angles, subspace, linear algebra
\end{abstract}

\section{Pendahuluan}

Dalam text-mining, salah satu model yang digunakan adalah model vektor (vector space model) [3]. Dalam model ini, sudut antara dua vektor merupakan salah satu alat yang digunakan. Misalnya dalam mesin pencari search engine, sudut digunakan untuk mengukur seberapa dekat vektor pencari relatif terhadap corpus [2]. Misalnya, model ini digunakan untuk membandingkan dua buah dokumen sebagai penyaringan plagiarisme tahap awal, dimana similaritas dari kedua dokumen diukur berdasarkan ukuran sudut yang dibentuk oleh dokumen yang dibandingkan. [10]

Model lain, adalah Model Matriks [1] [4] yang menggunakan representasi vektor dari Matriks, sehingga penghitungan sudut antara dua matriks tidak beda dengan sudut antara vektor yang biasa. Cara penghitungan sudut demikian, menghilangkan makna dari efek kolom matriks, mengingat penggunaan model Matriks diusulkan agar model bisa dipandang sebagai sekumpulan vektor. Dalam [8], proses penyaringan plagiarisme dokumen diusulkan menggunakan matriks sebagai model dokumen yang tersusun atas paragraf sebagai kolomnya. Diusulkan cara mengukur sudut antara dua dokumen, dengan cara menghitung sudut antara dua subruang ruang kolom dari matriks.

2000 Mathematics Subject Classification: 15A60; 15A57; 15A18 Received: 03-05-2019, accepted: 20-06-2019. 
Dengan memanfaatkan formula sudut antara dua subruang, didapatkan sepasang sudut antara dua matriks, yang secara berturutan dihitung berdasarkan sudut antara dua subruang kolom dan sudut antara dua subruang baris dari kedua matriks.

Organisasi Tulisan. Pengertian sudut antara dua subruang dan rumus kosinus sudutnya. Pemanfaatan rumus sudut antara dua subruang untuk menghitung sudut antara dua subruang kolom, maupun dua subruang baris dari dua matriks. Diberikan beberapa contoh dengan kalkulasi menggunakan Octave, skrip Octave diberikan pada Lampiran agar dapat direproduksi hasil perhitungannya. Simpulan yang juga merangkumkan hal yang akan dilakukan.

$A, B \in R^{m, n}:$ Matriks berukuran $m \times n$.

\section{SUdUT ANTARA DUA MATRIKS}

2.1. Rumus Sudut Antara Dua Subruang ([5],[6],315). Misalkan $(X,<., .>)$ adalah ruang hasil kali dalam berdimensi 2 atau lebih, $U=\operatorname{span}\left\{u_{1}, u_{2}, \cdots, u_{p}\right\}$ dan $V=\operatorname{span}\left\{v_{1}, v_{2}, \cdots, v_{q}\right\}$ adalah 2 subruang di $X$ dimana $1 \leq p \leq q<\infty$. Misalkan pula bahwa $\left\{u_{1}, u_{2}, \cdots, u_{p}\right\}$ dan $\left\{v_{1}, v_{2}, \cdots, v_{q}\right\}$ adalah ortonormal, maka $\theta$ adalah sudut antara subruang $U$ dan $V$, yang diberikan sebagai berikut.

$$
\cos ^{2}(\theta)=\operatorname{det}\left(M M^{T}\right)
$$

dengan $\left.M:=\left[<u_{i}, v_{k}\right\rangle\right]=\left[u_{i}^{T} * v_{k}\right]$ adalah matriks berukuran $p \times q$, dan $M^{T}=\left[v_{k}^{T} * u_{i}\right]$. Perhatikan bahwa, untuk kasus $p=q$, rumus sudut menjadi:

$$
\cos (\theta)=|\operatorname{det}(M)|
$$

2.2. Dekomposisi Nilai Singular (Singular Value Decomposition, SVD)[7]. Gilbert Strang [11] dalam tulisan eksposisinya terkait dekomposisi matriks, mencantumkan Dekomposisi Nilai Singular (Singular Value Decomposition, SVD) sebagai salah satu dekomposisi matriks yang penting. Dekomposisisi nilai singular dari matriks $A$ dan $B$, adalah [7] :

$$
\begin{aligned}
& A=U_{A} S_{A} V_{A}^{T}, U_{A} \in R^{m, p}, S_{A} \in R^{p, p}, V_{A}^{T} \in R^{p, n}, \\
& B=U_{B} S_{B} V_{B}^{T}, U_{B} \in R^{m, q}, S_{B} \in R^{q, q}, V_{B}^{T} \in R^{q, n}
\end{aligned}
$$

dengan $U_{A}, U_{B}, V_{A}$, dan $V_{B}$, merupakan matriks ortonormal. Sedangkan matriks $S_{A}$, dan $S_{B}$, merupakan matrik diagonal dengan entri diagonalnya merupakan nilai singular dari $A$ dan $B$. Perhatikan bahwa $U_{A}, U_{B}$ secara berturutan merupakan basis ortonormal ruang kolom dari $A$ dan $B$. Demikian pula dengan $V_{A}, V_{B}$ secara berturutan merupakan basis ortonormal ruang baris dari $A$ dan $B$. Selanjutnya, kita katakan dekomposisi SVD.

\subsection{Hasil Utama.}

2.3.1. Sudut antara dua subruang kolom. Tuliskan:

$$
U_{U A}:=U_{A}, V_{U B}:=U_{B} .
$$

Misalkan $U_{U A}=\left[u_{1} u_{2} \cdots u_{p}\right]$ dan $V_{U B}=\left[v_{1} v_{2} \cdots v_{q}\right]$, dituliskan sebagai susunan kolom. Sudut antara subruang kolom dari $A$ dan $B$ dapat dihitung melalui rumus kosinus :

$$
\cos ^{2}(\theta)=\operatorname{det}\left(M M^{T}\right)
$$

dengan

$$
M=\left[U_{U A}^{T} V_{U B}\right]
$$


2.3.2. Sudut antara dua subruang baris. Ambil:

$$
U_{V A}:=V_{A}, V_{V B}:=V_{B} .
$$

Misalkan $U_{V A}=\left[u_{1} u_{2} \cdots u_{p}\right]$ dan $V_{V B}=\left[v_{1} v_{2} \cdots v_{q}\right]$, dituliskan dalam susunan kolom. Sudut antara subruang baris dari $A$ dan $B$ dapat dihitung melalui rumus kosinus :

$$
\cos ^{2}(\phi)=\operatorname{det}\left(M M^{T}\right)
$$

dengan

$$
M=\left[U_{V A}^{T} V_{V B}\right]
$$

Sudut $\theta$ dan $\phi$, secara berturutan disebut sudut kiri (subruang kolom) dan sudut kanan (subruang baris) antara dua matriks. Selanjutnya, pasangan $(\theta, \phi)$, didefinisikan sebagai pasang sudut antara dua matriks.

Dari faktor diagonal dekomposisi SVD, misalkan $d_{A}=\operatorname{diag}\left(S_{A}\right)$ dan $d_{B}=\operatorname{diag}\left(S_{B}\right)$. Maka jarak antara kedua matriks adalah :

$$
\rho(A, B)=\left\|d_{A}-d_{B}\right\|
$$

dengan ||.|| merupakan jarak Euklidean dari sebuah vektor, yang ekivalen dengan jarak antara dua matriks dalam Frobenius norm [9].

2.4. Contoh. Diberikan 4 buah contoh, dengan 3 contoh pertama dibangkitkan dari 2 buah matriks berukuran $3 \times 3$. Matriks pertama berasal dari matriks Hilbert, yang kedua dari matriks Pascal segitiga bawah.

Matriks HO, sebuah matrix Hilbert berukuran $3 \times 3$ yang simetrik,

$$
\mathrm{HO}=\left(\begin{array}{lll}
1.00000 & 0.50000 & 0.33333 \\
0.50000 & 0.33333 & 0.25000 \\
0.33333 & 0.25000 & 0.20000
\end{array}\right),
$$

dengan dekomposisi $\mathrm{SVD}: \mathrm{HO}=\mathrm{UHO} * \mathrm{SHO} * \mathrm{VHO}^{T}$, dengan matriks faktornya:

$$
\begin{gathered}
\mathrm{UHO}=\left(\begin{array}{rrr}
-0.82704 & 0.54745 & 0.12766 \\
-0.45986 & -0.52829 & -0.71375 \\
-0.32330 & -0.64901 & 0.68867
\end{array}\right) ; \quad \text { SHO }=\left(\begin{array}{ccc}
1.4083189 & 0 & 0 \\
0 & 0.1223271 & 0 \\
0 & 0 & 0.0026873
\end{array}\right) \\
\mathrm{VHO}=\left(\begin{array}{rrr}
-0.82704 & 0.54745 & 0.12766 \\
-0.45986 & -0.52829 & -0.71375 \\
-0.32330 & -0.64901 & 0.68867
\end{array}\right)
\end{gathered}
$$

Matriks P1, merupakan matriks Pascal berukuran $3 \times 3$, berupa segitiga bawah,

$$
\mathrm{P} 1=\left(\begin{array}{ccc}
1 & 0 & 0 \\
1 & -1 & 0 \\
1 & -2 & 1
\end{array}\right)
$$

dengan dekomposisi SVD: $\mathrm{P} 1=\mathrm{UP} 1 * \mathrm{SP} 1 * \mathrm{VP} 1^{T}$, dengan matriks faktornya:

$$
\begin{gathered}
\mathrm{UP1}=\left(\begin{array}{rrr}
-0.19382 & 0.81650 & 0.54384 \\
-0.47225 & 0.40825 & -0.78123 \\
-0.85989 & -0.40825 & 0.30646
\end{array}\right) ; \quad \mathrm{SP} 1=\left(\begin{array}{ccc}
2.80588 & 0 & 0 \\
0 & 1.00000 & 0 \\
0 & 0 & 0.35639
\end{array}\right) \\
\mathrm{VP1}=\left(\begin{array}{rrr}
-0.54384 & 0.81650 & 0.19382 \\
0.78123 & 0.40825 & 0.47225 \\
-0.30646 & -0.40825 & 0.85989
\end{array}\right)
\end{gathered}
$$


2.4.1. Contoh 1. Sudut antara 2 matriks dg rank 1. Misalkan, H01 adalah matriks dengan rank 1, yang dikonstruksi dari komponen pertama dekomposisi SVD matriks Hilbert berukuran $3 \times 3$ di atas. Sementara P11 adalah matriks dengan rank 1, yang dikonstruksi dari komponen pertama dekomposisi SVD matriks Pascal berukuran $3 \times 3$ di atas.

$$
\mathrm{H} 01=\left(\begin{array}{lll}
0.96329 & 0.53562 & 0.37656 \\
0.53562 & 0.29782 & 0.20938 \\
0.37656 & 0.20938 & 0.14720
\end{array}\right) ; \quad \mathrm{P} 11=\left(\begin{array}{ccc}
0.29577 & -0.42487 & 0.16667 \\
0.72063 & -1.03518 & 0.40608 \\
1.31216 & -1.88491 & 0.73942
\end{array}\right)
$$

Sudut antara dua subruang kolom dari kedua matriks, dihitung dengan rumus kosinus sudut dari (1), sehingga diperoleh

$$
\cos ^{2}(\theta)=0.42964, \theta=0.8559,
$$

sementara dengan menggunakan rumus kosinus sudut dari (2), diperoleh hasil yang sama, yaitu

$$
\cos (\theta)=0.65547, \theta=0.85599 .
$$

Sementara sudut antara dua subruang baris, dengan rumus kosinus sudut (1), diperoleh

$$
\cos ^{2}(\phi)=0.035949, \quad \phi=1.38000,
$$

sementara dengan menggunakan rumus kosinus sudut (2), diperoleh hasil yang sama, yaitu

$$
\cos (\phi)=0.18960, \quad \phi=1.3800 .
$$

Sehingga pasang sudut antara kedua matriks

$$
(\theta, \phi)=(0.8559,1.3800) .
$$

Juga diperoleh jarak antara kedua matriks, menggunakan rumus (3):

$$
\rho=1.3976 .
$$

2.4.2. Contoh 2. Sudut antara 2 matrix dg rank 2. Misalkan, H02 adalah matriks dengan rank 2, yang dikonstruksi dari komponen pertama dan kedua dekomposisi SVD matriks Hilbert berukuran $3 \times 3$ di atas. Sementara P12 adalah matriks dengan rank 2, yang dikonstruksi dari komponen pertama dan ketiga dekomposisi SVD matriks Pascal berukuran $3 \times 3$ di atas.

$$
\mathrm{H} 02=\left(\begin{array}{lll}
0.99996 & 0.50024 & 0.33310 \\
0.50024 & 0.33196 & 0.25132 \\
0.33310 & 0.25132 & 0.19873
\end{array}\right) ; \quad \mathrm{P} 12=\left(\begin{array}{lll}
0.33333 & -0.33333 & 0.33333 \\
0.66667 & -1.16667 & 0.16667 \\
1.33333 & -1.83333 & 0.83333
\end{array}\right)
$$

Sudut untuk subruang kolom, dengan menggunakan rumus kosinus sudut (1), diperoleh

$$
\cos ^{2}(\theta)=0.21931, \theta=1.0834,
$$

sedangkan menggunakan rumus kosinus sudut (2), diperoleh hasil yang sama, yaitu

$$
\cos (\theta)=0.46830, \theta=1.0834 \text {. }
$$

Untuk subruang baris, dengan menggunakan rumus kosinus sudut (1), diperoleh

$$
\cos ^{2}(\phi)=0.21931, \quad \phi=1.0834,
$$

sementara dengan menggunakan rumus kosinus sudut (2), diperoleh hasil yang sama, yaitu

$$
\cos (\phi)=0.46830, \quad \phi=1.0834 .
$$

Sehingga pasang sudut antara kedua matriks

$$
(\theta, \phi)=(1.0834,1.0834) .
$$

Juga diperoleh jarak antara kedua matriks, menggunakan rumus (3) :

$$
\rho=1.3976 .
$$


2.4.3. Contoh 3. Sudut antara matriks dengan rank berbeda. Misalkan, H01 adalah matriks dengan rank 1, yang dikonstruksi dari komponen pertama dekomposisi SVD matriks Hilbert berukuran $3 \times 3$ di atas. Sementara P12 adalah matriks dengan rank 2, yang dikonstruksi dari komponen kedua dan ketiga dekomposisi SVD matriks Pascal berukuran $3 \times 3$ di atas.

$\mathrm{H} 01=\left(\begin{array}{rrr}0.96329 & 0.53562 & 0.37656 \\ 0.53562 & 0.29782 & 0.20938 \\ 0.37656 & 0.20938 & 0.14720\end{array}\right) ; \quad \mathrm{P} 12=\left(\begin{array}{rrr}0.704234 & 0.424866 & -0.166667 \\ 0.279368 & 0.035181 & -0.406082 \\ -0.312164 & -0.115087 & 0.260585\end{array}\right)$ kiri

Untuk subruang kolom, dengan menggunakan rumus kosinus sudut (1), diperoleh sudut

$$
\cos ^{2}(\theta)=0.57036, \theta=0.71481 \text {. }
$$

Sedangkan untuk subruang baris, dengan menggunakan rumus kosinus sudut dari (1), didapatkan sudut kanan

$$
\cos ^{2}(\phi)=0.96405, \quad \phi=0.19076 .
$$

Sehingga pasang sudut antara kedua matriks

$$
(\theta, \phi)=(0.71481,0.19076) \text {. }
$$

Jarak antara kedua matriks, didapatkan dari (3) :

$$
\rho=0.40832 \text {. }
$$

2.4.4. Contoh 4. Pada contoh terakhir ini, digunakan dua buah matriks berukuran $500 \times 400$, yang dibangkitkan secara sintetis. Dapat dilihat secara lengkap di Lampiran. Kedua matriks tersebut, dinamai hurufI dan hurufP. kolom),

Dengan menghitung rumus kosinus sudut (1), diperoleh untuk sudut kiri (subruang

$$
\cos ^{2}(\theta)=1.00000, \theta=1.1921 e-07 .
$$

Sedangkan untuk sudut kanan (subruang baris), dengan menghitung rumus kosinus sudut (1), diperoleh

$$
\cos ^{2}(\phi)=0.62280, \quad \phi=0.66133 .
$$

Sehingga pasang sudut antara kedua matriks

$$
(\theta, \phi)=(1.1921 e-07,0.66133) .
$$

Juga diperoleh jarak antara kedua matriks, dengan rumus (3):

$$
\rho=9.7482 e+04
$$

\section{Simpulan}

Diperlihatkan bahwa dengan memanfaatkan ruang kolom dan ruang baris, dapat didefinisikan sepasang sudut antara dua matriks berukuran sama dengan memanfaatkankan rumus sudut antara dua subruang. Sementara jarak secara otomatis diperoleh pada saat menghitung faktorisasi untuk mendapatkan pasang sudut antara dua matriks.

Aplikasi pasang sudut antara dua matriks, dapat digunakan untuk membandingkan dokumen diukur menggunakan konsep sudut dalam text-mining. Perbandingan dokumen dalam [8], hanya menggunakan sudut antara dua Matriks berdasarkan sudut antara dua ruang kolom. Aplikasi lain adalah untuk menghitung sudut antara dua gambar berukuran sama, yang akan dilaporkan pada tulisan lain.

Perluasan ke ruang Hilbert berdimensi tak hingga, menghitung sudut antara dua operator Hilbert-Schmidt yang merupakan operator kompak di ruang Hilbert yang separabel. Bahasan ini, akan disampaikan di tulisan yang akan datang. 


\section{Daftar Pustaka}

[1] Antonellis, I., Gallopoulos, E., 2006,Exploring Term-Document Matrices from Matrix Models in Text Mining. Greece: University of Patras.

[2] Berry, M.W., Browne, M., 1992,Understanding Search Engines: Mathematical Modelling and Text Retrieval. Philadelphia: Society for Industrial and Applied Mathematics, 1992

[3] Berry, M.W., Dumais, S.T., and OBrien, GW., Using linear algebra for intelligent information retrieval, SIAM Review, 374, 573-595.

[4] Berry, M.W., Drmac, Z., and Jessup, E.R., 1999, Matrices, vector spaces, and information retrieval, SIAM Review, 41(2),335-362.

[5] Gunawan, H., Neswan, O.,2005, On Angles Between Subspaces Of Inner Product Spaces. Vol. 11, No. 2. Indonesia: Math. Society (MIHMI).

[6] Gunawan, H., Neswan, O., Setya-Budhi W., 2005, A Formula for Angles Between Two Subspaces of Inner Product Spaces, Beitrge Algebra Geom. Vol. 46(2), 311-320.

[7] Leon, S.J., 1998, Aljabar Linear dan Aplikasinya. Edisi ke-5. A. Bondan, Penerjemah; Erlangga.

[8] Lestari, P.D. R., Agustian, R, Gafriadi,R., Febriyanti,A., dan Garnadi, A.D., 2007, Model Vektor dan Matriks dari Dokumen Serta Sudut antara Dua Vektor dan Dua Subruang untuk Menduga Dini Plagiarisme Dokumen, Manuskrip, https://dx.doi.org/10.31227/osf.io/hmntg

[9] Muchlis, A., Analisis Matriks, Dept. Matematika, FMIPA-ITB, 2016

[10] Rosliyanti, P.P., Alban, M., Agustian, R., Penerapan Konsep Dasar Aljabar Linear Untuk Menduga Terjadinya Plagiarisme. Makalah PKMI. Dir.Penelitian dan Pengabdian kepada Masyarakat, Depdiknas. Bogor: IPB, 2006

[11] Strang, G., 2018,Multiplying and Factoring Matrices, 125(3), 223-230, The American Mathematical Monthly.

\section{LAMPIRAN}

\subsection{Lampiran 1.}

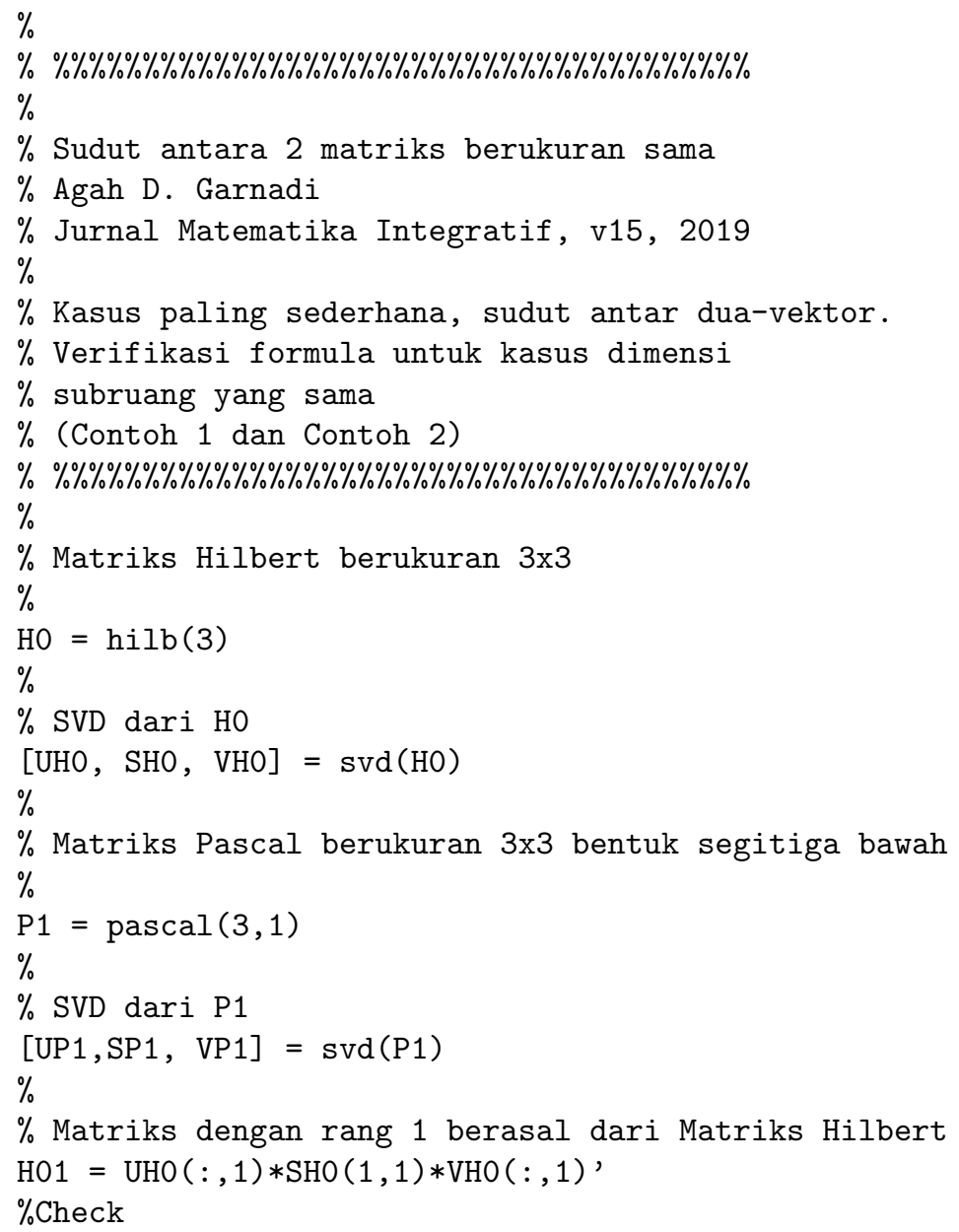


$\operatorname{rank}(\mathrm{H} 01)$

$\%$ Matriks dengan rang 1 berasal dari Matriks Pascal segitiga bawah $\mathrm{P} 11=\operatorname{UP} 1(:, 1) * \operatorname{SP} 1(1,1) * \operatorname{VP} 1(:, 1)$ '

$\%$ Check

$\operatorname{rank}(\mathrm{P} 11)$

$\%$

$\%$ Hitung matriks $M$ untuk sudut antar subruang kiri

$\%$

$\mathrm{M}=\mathrm{UHO}(:, 1)^{\prime} * \mathrm{UP} 1(:, 1)$

Cos2Theta $=\operatorname{det}\left(\mathrm{M} * \mathrm{M}^{\prime}\right)$

Theta $=\operatorname{acos}(\operatorname{sqrt}(\operatorname{Cos} 2$ Theta $))$

$\%$

$\% \mathrm{p}=\mathrm{q}$

CosTheta2 $=\operatorname{abs}(\operatorname{det}(\mathrm{M}))$

Theta2 $=\operatorname{acos}($ CosTheta2 $)$

$\%$

$\%$ Hitung matriks $M$ untuk sudut antar subruang kanan

$\%$

$\mathrm{M}=\operatorname{VHO}(:, 1)^{\prime} * \mathrm{VP} 1(:, 1)$

Cos $2 \mathrm{Phi}=\operatorname{det}\left(\mathrm{M} * \mathrm{M}^{\prime}\right)$

$\mathrm{Phi}=\operatorname{acos}(\operatorname{sqrt}(\operatorname{Cos} 2 \mathrm{Phi}))$

$\%$

$\% \mathrm{p}=\mathrm{q}$

CosPhi2=abs $(\operatorname{det}(\mathrm{M}))$

Phi2 $=\operatorname{acos}(\operatorname{CosPhi2})$

\% Jarak dari kedua matriks dg rang 1

rho $=\operatorname{norm}(\operatorname{SHO}(1,1)-\operatorname{SP1}(1,1))$

\subsection{Lampiran 2.}

\% \% \% \% \% \% \% \% \% \% \% \% \% \% \% \% \% \% \% \% \% \% \% \% \% \% \% \% \% \% \% \% \% \% \% \% \% \% \% \% \% \%

$\%$

$\%$ Sudut antara 2 matriks berukuran sama

$\%$ Agah D. Garnadi

\% Jurnal Matematika Integratif, v15, 2019

$\%$

$\%$ Contoh 3:

$\%$ Matriks dengan rang berbeda

$\%$

$\%$ \% \% \% \% \% \% \% \% \% \% \% \% \% \% \% \% \% \% \% \% \% \% \% \% \% \% \% \% \% \% \% \% \% \% \%\%\% \% \%

$\%$

$\%$

$\%$ Matriks Hilbert berukuran $3 \times 3$

$\%$

$\mathrm{HO}=\mathrm{hilb}(3)$

$\%$

$\%$ SVD dari $\mathrm{HO}$

$[\mathrm{UHO}, \mathrm{SHO}, \mathrm{VHO}]=\operatorname{svd}(\mathrm{HO})$

$\%$

$\%$ Matriks Pascal berukuran $3 \times 3$ bentuk segitiga bawah

$\%$

$\mathrm{P} 1=\operatorname{pascal}(3,1)$ 
$\%$

$\%$ SVD dari P1

$[\mathrm{UP} 1, \mathrm{SP} 1, \mathrm{VP} 1]=\operatorname{svd}(\mathrm{P} 1)$

$\%$

$\%$ Matriks dengan rang 1 berasal dari Matriks Hilbert

$\mathrm{HO} 1=\mathrm{UHO}(:, 1) * \mathrm{SHO}(1,1) * \mathrm{VHO}(:, 1)$ '

$\%$ Check

rank (H01)

\% Matriks dengan rang 2 berasal dari Matriks Pascal segitiga bawah

$\mathrm{P} 12=\operatorname{UP} 1\left(:,\left[\begin{array}{ll}2 & 3\end{array}\right]\right) *[\operatorname{SP} 1(2,2) \quad 0 ; 0 \quad \operatorname{SP} 1(3,3)] * \operatorname{VP} 1\left(:,\left[\begin{array}{ll}2 & 3\end{array}\right]\right)$ '

$\%$ Check

rank (P12)

$\%$

$\%$ Hitung matriks $M$ untuk sudut antar subruang kiri

$\mathrm{M}=\operatorname{UHO}(:, 1)^{\prime} * \operatorname{UP} 1\left(:,\left[\begin{array}{ll}2 & 3\end{array}\right]\right)$

Cos2Theta $=\operatorname{det}\left(\mathrm{M} * \mathrm{M}^{\prime}\right)$

Theta $=\operatorname{acos}(\operatorname{sqrt}(\operatorname{Cos} 2$ Theta $))$

$\%$

$\% \mathrm{p} \backslash$ neq $\mathrm{q}$

size (M)

$\%$

$\%$ Hitung matriks $M$ untuk sudut antar subruang kanan

$\mathrm{M}=\operatorname{VHO}(:, 1)^{\prime} * \operatorname{VP} 1\left(:,\left[\begin{array}{ll}2 & 3\end{array}\right]\right)$

Cos $2 \mathrm{Phi}=\operatorname{det}\left(\mathrm{M} * \mathrm{M}^{\prime}\right)$

$\mathrm{Phi}=\operatorname{acos}(\operatorname{sqrt}(\operatorname{Cos} 2 \mathrm{Phi}))$

$\%$

$\%$ p neq $\mathrm{q}$

size (M)

$\%$

$\%$ Jarak dari kedua matriks

rho $=\operatorname{norm}([\operatorname{SHO}(1,1) 0 ; 00]-[\operatorname{SP} 1(2,2) 0 ; 0 \quad \operatorname{SP} 1(3,3)])$

\subsection{Lampiran 3.}

$\%$

$\% \quad \% \% \% \% \% \% \% \% \% \% \% \% \% \% \% \% \% \% \% \% \% \% \% \% \% \% \% \% \% \% \% \% \% \% \% \% \% \% \%$

$\%$

$\%$ Sudut antara 2 matriks berukuran sama

$\%$ Agah D. Garnadi

\% Jurnal Matematika Integratif, v15, 2019

$\%$

$\%$ Contoh 4:

$\%$ Gambar huruf I dan P

$\%$

$\%$ \% \% \% \% \% \% \% \% \% \% \% \% \% \% \% \% \% \% \% \% \% \% \% \% \% \% \% \% \% \% \% \% \% \% \% \% \% \% \% \% \% \% \%

$\%$

$\%$

$\%$ Huruf I

$\%$

huruf $I=\operatorname{zeros}(500,400)$;

$\operatorname{hurufI}(50: 450,150: 250)=200$;

$\%$

$\%$ Huruf P 
$\%$

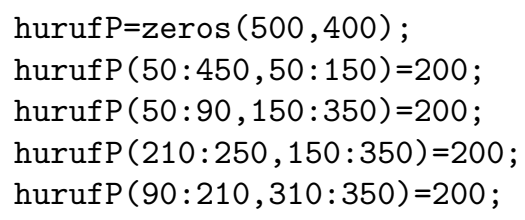

